\title{
Dialectical Relationship between System Collaboration and Coordination
}

\author{
Shao Li-jin \\ Fuzhou Melbourne Polytechnic, \\ Fuzhou 350108, China \\ School of Economic \& Management, Fuzhou University \\ Fuzhou 350116, China \\ E-mail: 49364408@qq.com
}

\author{
Chen Zhong \\ Fujian Normal University
}

\begin{abstract}
The concepts of the system collaboration and coordination are confused in the theoretical cycle. The concepts of collaboration and coordination and the difference and connection between them are analyzed, and six dialectical relationships are proposed: Collaboration emphasizes cooperative behavior and coordination emphasizes state or relationship; Collaboration emphasizes multi-win-win situation and coordination emphasizes equilibrium and overall optimization; Coordination is of external nature, and collaboration is of internal nature; From coordination to collaboration, coordination is the means to achieve collaboration; Coordination which can drive collaboration is the guarantee of system collaborative precession; Collaboration which can promote coordination is the inevitable requirement of coordinated development. In this way, it is conductive to clarifying the concepts of them, and the researches on the issues related to collaboration or coordination can be made well in the true sense through rationally recognizing the difference and connection between them.
\end{abstract}

Keywords-System; Collaboration; Coordination; Dialectical relationship

\section{INTRODUCTION}

With the "harmonious development" proposed in the Fifth Plenary Session and the "collaboration" proposed in the report at the 18th National Congress of the Communist Party of China, a large number of research programs under the name of "collaboration" or "coordination" have been blossomed, but we can clearly realize the existence of confusion between the two concepts. In the following, we will list the understandings of some scholars in the management science cycle on the concepts of collaboration and coordination, and these opinions are representative. Obviously, it is very beneficial to clarify the difference between these concepts for our research on collaboration degree and collaboration diagnosis.

\section{ABOUT THE CONCEPT OF COLLABORATION}

From ancient Greek's semantic interpretation to China's Shuo Wen Jie Zi, Ci Hai and Xinhua Chinese Dictionary, all of them define "collaboration" as "a harmonious and coordinated cooperative behavior." In recent years, Western countries have generally emphasized that collaboration is an interdepartmental and cross-subject cooperative behavior.

However, Higor Ansoff, an expert on strategic theory research in the United States, firstly proposed the concept of "collaboration" in 1965, he believed that collaboration is a process during which the overall goal can be achieved the through resource sharing and coordinated operation after various systems are organized together [1]. Afterwards, Haken (1971) believed that collaboration is a cooperative behavior by which the system-wide polymerization can be formed after each subsystem within a complex system generates the individual effect beyond itself, so that the system can move in an identical and orderly manner [2]. The degree of this cooperative action is the degree of collaboration. Michael Porter (1977) explained the collaboration with the concept of value chain and paid more attention to the influence of internal management on value creation, and he also believed that the enterprises can gain a competitive advantage by building the relationship between internal business units and the connection between the enterprises [3]. Buzzell RD and Gale B T. (1989) defined "collaboration" from the perspective of enterprise cluster and believed that collaboration is the overall business performance of the enterprise cluster relative to the business performance of various independent components formed after simple summary [4]. Stank and Keller (2001) believed that collaboration is the process of making decisions among members, during which, the results will be allocated jointly, that is, two or more members or organizations will work together and share a common vision and resources in order to achieve a common goal [5]. Miles et al. pointed out that "collaboration" is a different process in the philosophical sense from "cooperation", the expected result of collaboration is relatively clear, and the allocation of the future returns can be consulted in advance, while the parties related to the cooperation should carry out activities based on their own interests [6]. In addition, Von Krogh also pointed out that collaboration often involves in unpredictable results and relies heavily on trust and a shared commitment to honest and fair 
values [6]. Compared with "cooperation", the parties related to collaboration must treat the interests of the other parties as much as their own interests, and "collaboration" places greater emphasis on the collaboration in order to achieve the same goal and on the basis of risk sharing and benefit sharing as well as the fair and honest cooperation environment. Chissick M \& Harrington J (2004) proposed that collaboration is an advanced stage of cooperation and collaboration development from the perspective of system science, which reflects the coordination degree and the overall dependence between the systems or elements and can result in cooperation therefrom so that the effect of the overall system which cannot be reached by the single subsystem can be achieved [8]. Li Zhonglian (1987), a Chinese scholar, believed that collaboration is defined as the cooperation, coordination, synchronization and complementarity between the various elements of the system [9]. Du Dong (2008) proposed that coordination refers to the process of accomplishing a certain goal consistently through coordinating two or more different resources or individuals [10].

In summary, the author believes that collaboration is a kind of collective cooperative behavior with consistent goals, equal relationships, orderly actions, appropriate coordination, the complementary advantages and mutual benefit.

\section{ABOUT THE CONCEPT OF COORDINATION}

The original meaning of coordination refers to "perfect harmony and good coordination", which describes the benign relationship between the various elements within the system [10]. For the meaning of system coordination, some experts and scholars have made different definitions and expressions. From the perspective of management science, coordination is considered as a verb, which is a means; from the perspective of economics, coordination is considered as a state of equilibrium; from the perspective of system science, coordination refers to a placatory or harmonious mutual collaboration and coordination relationship between systems or between elements.

At earlier stage, the word "coordination" was occurred in the six major management functions mentioned in the book General and Industrial Management written by Fayol, he believed that "coordination refer to linking, uniting and reconciling all activities and forces", i.e. coordination means that all works of an enterprise must be harmoniously coordinated so as to facilitate the smooth operation of the enterprise and facilitate the success of the enterprise [4]. According to Fayol's opinion, coordination is a balancing act, which can make spending equal to income so that the equipment can match with the achievement of the production goals and the coordination between sales and production can be ensured. Afterwards, Meng Qingsong and Han Wenxiu (1999), Chinese scholars, believed that coordination refers to the harmony between systems or elements forming the system during the process of development and evolution, and they further defined the coordination role and coordination mechanism [12]; Li Yan and Zeng Zhenxiang (2003) believed that coordination is a management function, which can adjust the interrelation of various activities in the whole organization focusing on the development goal of the organization so that these activities can be organically combined, the conflicts can be reduced, the mutual coordination can be achieved and the goal of the organization can be achieved [12]; Dai Shuyan and Huang Xinjian (2004) believed that coordination refers to the organic unity of the elements within the system and the harmonious, orderly and gradual rising of the material cycle [12]; Liu Yaobin and Song Xuefeng (2005) believed that system coordination refers to the harmony of various parameters among various layers and various subsystems within the system, the integration of structures and functions and the steady state of the physical energy flows between systems [12]; Li Jinying (2006) believed that, for a complex system, coordination refers to a benign state of the harmony among the elements of the system at one time or at certain times [12].

In summary, the author believes that coordination is both a state and a process. As a state, coordination refers to the harmonious or placatory relationship between the various constituent elements or subsystems that are coordinated and the achievement of an optimal overall effect; as a process, coordination is considered as a function or means of control and management, which can adjust the interrelation among the various constituent elements or subsystems that are coordinated to reduce the contradictions or reduce the contradictions or conflicts between them and enable the goals of the organization to be achieved.

The existence of the above concepts will inevitably cause some confusions to people, for example: What is collaboration? What is coordination? Is collaboration equal to coordination? What is the difference and relationship between them? Most of the current models used to evaluate the system cooperativity are coordination degree models, therefore, the dialectical relationship between collaboration and coordination must be clarified in order to evaluate the system cooperativity in a real sense and establish the collaborative management theory.

\section{DiALECTICAL RELATIONSHIP BETWEEN COLLABORATION AND COORDINATION}

"One singing a song and the others joining in the chorus should be coordinated, so do Gong and Shang (Gong and Shang refers to the two tones in ancient Chinese music)," it is a saying in the Records of the States in the Eastern Zhou Dynasty written by Feng Menglong, a litterateur in Ming Dynasty, which describes that one singing a song and the others joining in the chorus must be united and coordinated, and the Gong and Shang must also be coordinated so that a beautiful and harmonious music can be played. To a certain extent, it has illustrated the complementary relationship between collaboration and coordination. Then, when it comes to the dialectical relationship between them, the author firstly examined a series of relevant literature materials, made the relevant collation, then formed Table 3.1 was formed and finally obtained the differences and relations between collaboration and coordination after a comparative analysis on collaboration and coordination accordingly. The specific contents can be seen in the following table. 
TABLE I. COMPARATIVE ANALYSIS ON COLLABORATION AND COORDINATION

\begin{tabular}{|c|c|c|}
\hline Differences & \begin{tabular}{|c|} 
Collaboration \\
\end{tabular} & Coordination \\
\hline Definition & $\begin{array}{c}\text { Hacken's opinion: a cooperative behavior of } \\
\text { forming an overall polymerization by various } \\
\text { subsystems in a complex system in some } \\
\text { ways. }\end{array}$ & $\begin{array}{l}\text { The harmonious and symbiotic relationship between } \\
\text { various component elements and subsystems within the } \\
\text { system through complex and dynamic interactions. }\end{array}$ \\
\hline $\begin{array}{l}\text { Relationship } \\
\text { between elements } \\
\text { or subsystems of } \\
\text { the system }\end{array}$ & Equal and independent & Equal and independent or superior and subordinate \\
\hline Characteristics & $\begin{array}{l}\text { Consistent Intrinsic psychology and orderly } \\
\text { external behavior }\end{array}$ & Intrinsic harmony and equilibrium \\
\hline $\begin{array}{l}\text { Is it achieved in } \\
\text { virtue of external } \\
\text { force or not, }\end{array}$ & No, spontaneous & Yes \\
\hline Purpose & $\begin{array}{c}\text { To realize the systematic and orderly purpose } \\
\text { and achieve cooperation, win-win and all-win } \\
\text { results }\end{array}$ & $\begin{array}{c}\text { To reduce negative effects and reduce incitement, achieve } \\
\text { system equilibrium or balance, and achieve maximize } \\
\text { overall benefits. }\end{array}$ \\
\hline State & $\begin{array}{c}\text { The behavior is orderly and away from the } \\
\text { evenly distributed balance state }\end{array}$ & $\begin{array}{l}\text { The ideal state of the relationship, such as: a balanced, } \\
\text { harmonious and placatory relationship }\end{array}$ \\
\hline Object & $\begin{array}{c}\text { Individual and Individual (P-P), individual } \\
\text { and organization }(\mathrm{P}-\mathrm{O}) \text {, organization and } \\
\text { organization }(\mathrm{O}-\mathrm{O})\end{array}$ & $\begin{array}{l}\text { Element and element, element and system, system and } \\
\text { environment }\end{array}$ \\
\hline Scope & $\begin{array}{l}\text { Wide scope, cooperation, competition, } \\
\text { coordination, etc. }\end{array}$ & Narrow scope, adjustment, balance \\
\hline Source & $\begin{array}{l}\text { Dissipative structure theory, self-organization } \\
\text { theory and synergetics }\end{array}$ & Management theory \\
\hline
\end{tabular}

Obviously, through the above analysis, it can be seen that there are both differences and relationships between them, and there is also a certain dialectical relationship between them. Therefore, we must make a logical analysis so that we can really clarify the relationship between them.

\section{A. Collaboration Emphasizes Cooperative Behavior and Coordination Emphasizes the State or Relationship.}

Collaboration and coordination are key words that scholars have studied in recent years. Scholars in different fields may have different understandings on them, they seem similar, but different in reality. According to Haken's opinion, he believed that collaboration is a cooperative behavior of an overall polymerization by various subsystems in some ways. It emphasizes a collective behavior. However, with regard to coordination, many scholars believed that it is a harmonious and symbiotic state or relationship between the various component elements and subsystems within the system and it emphasizes a harmonious relationship.
B. Collaboration Emphasizes All-win Situation and Coordination Emphasizes Equilibrium and Overall Optimization.

In his "coordinated development view", Xi Jinping proposed that the coordination development can solve the unbalanced development problem, it is observed that the role of coordination is more focused on solving the balance or equilibrium problem, resolve various types of contradictions or conflicts, reduce the negative effects, reduce the incitement, gradually reach a balance and ultimately achieve the overall optimization; While collaboration emphasizes the close and orderly cooperation among the participants, their goals should be consistent, advantages should be complementary, the labors should be divided, cooperation should be taken, actions should be orderly, and win-win cooperation will be ultimately achieved.

\section{Coordination is of External nature and Collaboration is of Internal Nature.}

The relationship between the collaboration subjects is equal and independent, most of them are relationships on the horizontal level, and there is no affiliated relationship; There can be a superior and subordinate relationship between the coordination subjects on the vertical level, but also an equal relationship on the horizontal level, it is often necessary to use the power of superiors, while coordination does not require the intervention of anyone's external force. Therefore, coordination is of external nature and collaboration is of internal nature. 


\section{From Coordination to Collaboration, Coordination is a Means to Achieve Collaboration.}

The core of collaboration lies in the consistency of internal thoughts and the orderliness of external behaviors. Firstly, the consistency of internal thoughts can be understood as follows: in order to achieve smooth communication, full trust and strong cohesiveness among the various collaborative subjects, coordination needs to exist at all times. Secondly, the general operation mechanism of collaboration is "competitioncooperation-coordination". When there is conflict or contradiction between collaboration subjects in the process of cooperation or collaboration, it is necessary to reconcile the relationships between various parties related to conflicts or contradictions by means of coordination so as to make them tend to be harmonious, all parties reach a consensus and form a certain degree of cohesion so that the collaboration can be eventually achieved.

However, the various subsystems need to undergo a large number of coordination processes before the collaboration is actually achieved. By coordinating the relationships, action ideas and methods among various subsystems, an ideological consensus can be reached and the internal consistency can be gradually formed; through using coordination means and adjusting the subsystems in an unordered state, they can be coordinated in behavior or operation. Therefore, a coordinated state can be achieved by coordinating the internal and external aspects of each subsystem. For example: if a team is constituted by 5 basketball players who have never known each other and have abilities to complement each other, before they have not actually formed a team, the fighting power is naturally not strong. They must go through a series of training and coordination from the coach, so that they can reach an agreement on the goal in the match field, and ultimately win the game through their own division of labor and orderly cooperation, it is the so-called collaboration. Therefore, from collaboration to coordination, coordination is the means to achieve collaboration.

\section{E. Coordination which Can Drive Cooperation is the Guarantee of System Collaborative Precession.}

Collaborative precession refers to the transformation of the traditional all-out and fierce competitive mode of competitive systems or elements to cooperative and orderly cooperation state under which all parties in the competition will benefit from a win-win situation and advance together. However, through the application of opinions in the synergetics and dissipative structure theory, due to the parametric thresholds, the phase transition of the system will be naturally occurred. Then, once a certain parameter of the system reaches a certain threshold, the system will begin to be transited from stable state to unstable state and from the original disordered state to a new ordered state, therefore, there will be generally such a continuously circular and repeated spiral rising process in the system, i.e. "no collaboration $\rightarrow$ collaboration $\rightarrow$ no collaboration $\rightarrow$ collaboration.
Obviously, to achieve the collaborative precession, in addition to the mechanism of internal collaboration role of the system, the external environment or the so-called order parameters should also provide appropriate coordination and drive for the system, thereby providing a guarantee for the formation and orderly evolution of the self-organizing structure of the system [13]. Therefore, any open system must cannot be separated from repeated coordination and drive in order to maintain a certain degree of orderliness and achieve its collaborative precession goal. It can be seen that coordination is a strong guarantee for the system collaborative precession.

\section{F. Collaboration which can Promote Coordination is an Inevitable Requirement for Coordinated Development.}

Collaboration is a kind of dynamic relationship between subsystems and subsystems or things that can promote each other, cooperate with each other and move forward synchronously. When they form an orderly state, the collaboration will be produced. However, the purpose of coordination is to solve the problem of imbalance, and it is the internal demand for the sustainable and healthy development of the economic and social system. Therefore, collaboration can lead to orderliness and orderliness is a state of harmony and coordination, which will be conductive to narrowing the gap between them and ultimately resulting in the same and integrated situation, thereby the coordinated development will be promoted.

The so-called "coordinated development" means simply that development should be harmonious and balanced, and all aspects and links must be adapted to each other and promote each other. Regarding the issues related to the coordinated development, the national government has always attached great importance to them. At the beginning of reform and opening up, Comrade Deng Xiaoping once pointed out: "The tasks of modernization are manifold, and all aspects should be comprehensively balanced and cannot be developed independently. The Party Central Committee has vigorously promoted the coordinated development of Beijing, Tianjin, and Hebei, especially the construction of the Xiong'an New District related to "A millennial plan of national significance", which can unravel Beijing's functions unrelated to its status as national capital, promote the construction of the Yangtze River Economic Belt, promote the industrial upgrading and transfer, guide the industrial layout and division of labor, achieve the collaboration, and promote the coordinated development. Thus, it can be seen that the regional collaboration is an inevitable requirement for coordinated development.

Comrade Xi Jinping's "coordinated development view", Comrade Mao Zedong's On the Ten Major Relationships and even Marxist materialist dialectics express the same point of view, i.e. coordinated development is the only way to achieve the economic development and the powerful country. However, in order to achieve coordinated development, collaboration must be required. 


\section{CONCLUSION}

Whether it is natural system or social system and economic system, coordination and collaboration are necessary requirements for system development. Both of them seem similar to each other, but they are different in reality, and there is still a huge difference. Coordination emphasizes a cooperative relationship, while collaboration emphasizes a cooperative behavior. Therefore, in the process of concrete research and practice, we must avoid the confusion of concepts and rationally recognize the differences and connections between them, so that we can make a research on the issues related to the collaboration or coordination in the true sense and will not confuse them, which is also the purpose of writing this text.

\section{REFERENCES}

[1] Dong Hao, Zeng Jianqiu and Shen Mengru. The Analysis on the Construction of Industrial Innovation Complex System and the Collaboration Degree: With the Information and Communication Industry as a Case [J]. Studies in Science of Science, 2016, 34(8):11521160 .

[2] H. Haken. Advanced Synergetics [M]. Translated by Guo Zhian. Beijing: Science Press, 1989, 210-238.

[3] Michael Porter. Competitive Advantage [M]. Beijing: Huaxia Publishing House, 1997.

[4] Bai Liehu and Wang Xiaojun. The Historical Evolution of the View of Management Collaboration [J]. Enterprise Reform and Management, 2010, 26(12): 61-64.

[5] Fu Yanrong, Deng Nian, Peng Qiyuan, et al. A Review of Synergy Theory and Application Research [J]. Journal of Tianjing University of Technology and Education, 2015, 25(1):44-47.

[6] Chen Fang and Sui Jigang. The Collaborative Innovation and Evolution Research of Emerging Industries: With New Energy Vehicles as A Case [J]. Science Research Management, 2015, 36(1):26-33.

[7] Von Krogh, Care in knowledge creation [J], California Management Review, 1998, 40: 133-153.

[8] S W. CHISSICK, M and HARRINGTON, J eds. E-government: a practical guide to the legal issues. London: Sweet and Maxwell, 2004. ISBN 0-421-79460-7 (pbk): £69. xxvii, 526p [J]. Legal Information Management, 2004, 4:275-275.

[9] Li Zhonglian. The Discussion on the Synergetic Effect of Psychology [J]. Journal of Social Science of Hunan Normal University, 1987(5):1-6.

[10] Du Dong. The Collaboration, Collaborative Management and Collaborative Management System [J]. Modern Management Science, 2008(2):92-94.

[11] Sui Yinghui. Coordinated Development Theory [M]. Qingdao: China Ocean University Press, 1990: 20-21.

[12] Zhao Tao, Li Xuanyu. The Research on the Evaluation Model of Energy-Economy-Environment (3E) System Coordination Degree [J]. Journal of Beijing Institute of Technology (Social Science Edition), 2008, 10(2):11-16.

[13] Wang Jian, Han Jingnan, Hu Cheng, et al. The Symbiosis Model and Application Research of Urban Compound Ecosystem [J]. Chinese Journal of Population, Resources and Environment, 2012, v.22; No.141(s2):291- 296. 